\title{
Th. W. Adorno y la aniquilación del individuo
}

\author{
JOSÉ A. ZAMORA \\ Instituto de Filosofía del CSIC
}

Resumen. Th. W. Adorno y los demás autores de la Teoría Crítica supieron captar procesos sociales incipientes que no han hecho sino desplegarse y confirmarse con el tiempo. Frente a quienes denuncian sus supuestas aporías y exagerado negativismo, se reivindica aquí la actualidad de una de sus tesis más conocidas y discutidas, la de la aniquilación del individuo. El paso del capitalismo liberal al monopolista sirve de horizonte para analizar las contradicciones del individuo burgués y su constitución social. En una segunda parte se aborda la «debilidad del yo» como aquella configuración psíquica que se corresponde con la liquidación del individuo en la sociedad tardocapitalista. En el centenario del nacimiento de Th. W. Adorno valgan estas reflexiones de homenaje a un pensador y un pensamiento cada día más imprescindibles.

Th. W. Adorno es sin duda uno de los pensadores más influyentes del siglo XX. Sus escritos filosóficos, estéticos y de teoría social han inspirado más allá de las fronteras alemanas a incontables científicos sociales, teóricos del arte y filósofos. El centenario de su nacimiento, que en nuestro país ha pasando casi desapercibido, puede ser una ocasión propicia para reivindicar la actualidad de su pensamiento y para hacerlo justamente en torno a una de sus tesis más discutidas en la era de exaltación del individualismo.
Abstract. Th. W. Adorno and other Critical Theory authors knew well how to identify emerging social processes which have been unfolded and confirmed through time. Opposite to those who denounce his supposed apories and exaggerated negativism, it is defended here the present relevance of one of his more well known and discussed thesis, that of the annihilation of the subject. The transition from liberal to monopolist capitalism serves as framework for the analysis of the contradictions between the burgeois individual and its social constitution. In the second part, it is considered the issue of the «weakness of the self» as the psychic configuration correspondig to the liquidation of the individual in late capitalist society. In the centenary of Th. W. Adorno's birth, these reflections are intended as an homage to the thinker and its thinking, which appears nowadays as even more indispensable than ever.

Aunque el antisemitismo y la industria de la cultura constituyan los dos fenómenos sociales que centran la atención crítica de Adorno en la década de los años cuarenta, dichos fenómenos aparecen a sus ojos como exponentes sobresalientes de un mismo proceso civilizador y una forma de socialización que afecta de modo fundamental al valor y situación actual del individuo. En la civilización técnicamente avanzada y en la sociedad crecientemente organizada, independientemente de su color político o de diferencias culturales, se produce, a pesar de una apariencia de 
pluralismo y de formas de vida cada vez más individualistas ${ }^{1}$, una integración progresiva de la individualidad y se reducen las posibilidades de despliegue de lo sustancialmente singular y diferente. Es lo que lleva a Adorno a formular su discutida tesis de la «aniquilación del individuo» ${ }^{2}$.

\section{Del capitalismo liberal al capitalismo monopolista}

El concepto de individuo está asociado, al menos desde la modernidad, a la capacidad de autoconciencia, de autodeterminación y de autoexpresión de los seres humanos en cuanto miembros de la sociedad. Se trata de capacidades adquiridas gracias a la mediación social, pero también en tensión y resistencia frente a ella. Desde la modernidad estas dimensiones tienen, además, un carácter normativo. El individuo se constituye a través de la autonomía, se identifica prácticamente con ella. Así pues, es la sociedad burguesa la que posibilita y al mismo tiempo exige de cada uno de sus miembros que sean individuos autónomos en el sentido de que hagan valer sus intereses políticos y económicos y de que sean responsables de sí mismos. Esta responsabilidad afecta incluso al ámbito de los deseos y de la expresividad, pues también descansa sobre los individuos el propio proyecto de autorrealización, de felicidad ${ }^{3}$.

Existen un conjunto de factores que conducen a esta nueva forma social de ver al individuo: la libertad de comercio y de propiedad, que posee una gran significación económica y ha de ser garantizada políticamente, la disolución de la dependencia material, así como la concomitante ampliación de los espacios individuales de acción, la estructura familiar burguesa, etc. En este sentido, el «individuo debe su cristalización a las formas de la economía política, especialmente al mercado urbano» ${ }^{4}$. Estos y otros factores hacen que el individuo ya no sea percibido ante todo como miembro de un estamento y clase social, sino como tal ser individual. Esto encuentra expresión asimismo en el ámbito cultural: en el discurso filosófico se desarrolla la idea de sujeto trascendental, en la literatura aparecen las narraciones biográficas y autobiográficas, así como la perspectiva del narrador en primera persona, y en la pintura emerge el género del retrato. La nueva cultura burguesa tiene su fundamento en la idea de subjetividad, que representa el correlato cultural de la categoría social de individuo.

Sin embargo, el sujeto, realidad derivada, debe su existencia a los mismos poderes que están llevando a cabo diligentemente su disolución. La autodeterminación autárquica, que proclamaba la mayoría de edad del sujeto ilustrado frente a cualquier autoridad, estuvo ya desde el comienzo ligada al intercambio y la propiedad, que ahora en el capitalismo avanzado estrangulan casi toda la capacidad de autodeterminación. El capitalismo liberal preveía como medio de autodeterminación el «contrato», cuyo fundamento era la propiedad. Pero no se tomaron en cuenta las diferentes relaciones de propiedad como base de diferentes posibilidades de autodeterminación y se dejó a cargo de una «mano invisible» la corrección de las diferencias económicas. Este ideal ilustrado se vio desmentido por la realidad desde el primer momento. Así fue surgiendo una red de corporaciones intermedias y se fue haciendo cada vez mayor la intervención del Estado tendente a rectificar las disfunciones sociales. Todo ello iba acompañado del crecimiento de un aparato jurídico que concretaba la función directiva del Estado. Pero este proceso que debería asegurar la igualdad de posibilidades de autodeterminación de los individuos amenaza una vez desplegado con estrangularla en un mundo totalmente administrado, donde los expertos acumulan sobre sí toda la competencia de tomar decisiones y los poderes econó- 
micos poseen una capacidad de influjo casi irrestricta. De los individuos se espera que se comporten tal como exige el sentido común empleado en la administración y por ella. Es decir, el individuo sólo existe de manera mediada en cuanto parte de una institución u organización, que define el ámbito y las metas de su acción, y en cuanto receptor de decisiones de una administración, que programa su comportamiento de manera imperativa y exacta.

Es importante destacar que la contradicción es inherente al individuo burgués desde el comienzo ${ }^{5}$, contradicción entre las exigencias políticas universales y los intereses burgueses particulares, entre la esfera pública y la privada, etc., y sobre todo la contradicción de que su independencia va acompañada de la opresión de la mujer en el ámbito privado y de la explotación de los asalariados «libres» en el ámbito económico. Por ello el concepto de individuo es, en un sentido genuino, ideología: «El ideal antifeudal de la autonomía del individuo, que se refería a su autodeterminación política, se transformó dentro del entramado económico en aquella ideología, de la que dicho entramado necesitaba para mantener el orden y aumentar el rendimiento» 6 . Y el desarrollo económico $\mathrm{y}$ político no ha resuelto estas contradicciones, sino que las ha agudizado ${ }^{7}$. Al menos esto es lo que parece confirmar el desmoronamiento de la figura estrictamente liberal del capitalismo, que Adorno percibe en las primeras décadas del siglo XX. No sin ciertas reticencias, él también hace suyo el diagnóstico establecido por F. Pollock y asumido por M. Horkheimer en el exilio americano de que la tendencia monopolista de la economía estaba llevando a cabo una disolución del mercado y una sustitución del mismo por la intervención directa del poder político en la dirección de la economía, lo que evidentemente supuso una valoración equivocada de la evolución del sistema económico ${ }^{8}$. De todos modos, la transición hacia un capita- lismo monopolista suponía de hecho que los individuos y sus intereses conscientes perdían en gran medida importancia en cuanto fundamento del mercado. El sistema se volvía cada vez más independiente de la iniciativa de los sujetos económicos individuales. Ahora las exigencias planteadas al comportamiento de los individuos venían dictadas por los objetivos definidos por los cárteles económicos y las cuestiones sociales eran gestionadas por los grupos de poder en los consorcios empresariales, las administraciones estatales, los partidos y el ejército.

Mientras que en la fase estrictamente liberal la iniciativa de los empresarios individuales era el presupuesto para su existencia y permanencia en el mercado, en la fase monopolista esto deja de ser una exigencia. La reproducción del sistema económico depende sobre todo de las condiciones económicas globales y éstas a su vez del cambio tecnológico. Las nuevas condiciones tecnológicas de la producción promueven la monopolización del capital y ésta convierte en marginal la iniciativa privada del empresario individual, paradigma del sujeto económico y su actividad autónoma. No es que la hábil o torpe actuación individual sea indiferente para la supervivencia de las empresas, pero ésta depende mucho más de condiciones anónimas. La disponibilidad del capital necesario para la cada vez más decisiva innovación tecnológica se vuelve determinante. Al mismo tiempo la creciente intensidad del capital necesario para la modernización tecnológica promueve y sostiene el proceso de concentración económica que conduce a una situación en la que se encuentran enfrentados entre sí los grandes grupos empresariales casi monopolistas. Los empresarios individuales que no disponen de capital en esas dimensiones se hunden o pierden su autonomía.

Cuanto más grandes son las empresas, las instituciones y las organizaciones tanto mayor es la coacción a la minimización 
del riesgo y a la planificación, tanto más adquieren protagonismo aquellos tipos de carácter que no están guiados por la idea de autonomía económica como fundamento de la participación autoconsciente en la vida social y política, sino por la idea de integrarse en una institución que posibilite a aquellos que alcanzan una posición directiva participar del poder de la misma. Y la posibilidad de alcanzar una situación social que permita utilizar las formas establecidas de dominación para ejercer el poder crece con la disponibilidad a adaptarse a las estructuras de dominio.

Por otro lado, el crecimiento de la riqueza social, a pesar de la desigual distribución entre las clases sociales, favorece la aceptación de la propia situación económica y la integración de la clase trabajadora. La oposición a la apropiación del trabajo ajeno por los monopolios tiende a desaparecer, en entre otras razones porque dicha apropiación, gracias a las mejoras de la situación material, se ha vuelto más invisible. La predicción realizada por Marx en su teoría de la pauperización de proletariado ha quedado desmentida por el curso de los hechos, tal como constata Adorno hacia 1942 en sus reflexiones sobre la teoría de las clases sociales, un texto que sólo se publicaría póstumamente:

«Los proletarios tienen algo más que perder que sus cadenas. Su nivel de vida [...] no ha empeorado, sino mejorado. Menos tiempo de trabajo, mejor alimentación, vivienda y vestidos, protección de los miembros de la familia y de la propia vejez, una mayor esperanza de vida les han correspondido a los trabajadores con el desarrollo de las fuerzas técnicas de producción. Para nada se puede decir que el hambre les vaya a llevar necesariamente a una unión incondicional y a la revolución» ${ }^{9}$.

Sin embargo, la ausencia de la conciencia clase no es un síntoma de que hayan sido superadas las clases, sino que refleja de modo objetivo el nuevo enmas- caramiento de la dominación de clases, que ya en la concepción de Marx no está determinada por la conciencia, sino por la posición de las clases en relación a los medios de producción. Esta posición no hace sino confirmar que dicha dominación sigue existiendo. Es más, la concentración del capital hace crecer la diferencia de clases de modo objetivo y con ella la impotencia de amplias masas. Pero es esa misma impotencia la que permite al capital aparecer como expresión del conjunto de la sociedad y que, en cuanto instancia anónima de toda la sociedad, sea visto como representación del equilibrio de intereses de todos sus miembros y a los grupos dominantes como sus representantes.

No sin cierta ironía señala Adorno que los trabajadores empiezan a tener algo más que temer que a la deshumanización embrutecedora a causa del proceso de trabajo industrial: «La figura del trabajador que de noche retorna a casa bebido y maltrata a la familia ha sido desplazada al margen más extremo: su mujer ha de temer más que a él, al social worker que le aconseja» ${ }^{10}$. Bajo el manto de la civilización quedan integradas en la planificación económica y política las condiciones de trabajo y el entorno social como ámbitos organizados. Dicha planificación no tiene necesidad ya de un enmascaramiento ideológico de las contradicciones de clase para estabilizar el sistema. Se dispone a controlar la economía psíquica de los trabajadores. De este modo, la deshumanización sobrevive a través de su aparente superación. El velo encubridor de la tecnología modela al trabajador más a fondo que los procesos de trabajo físicamente demoledores de la primera industrialización, y la cultura de masas «simplemente los vuelve a formar tal como ellos ya son de todos modos bajo la coacción del sistema, controla las brechas, al adversario oficial de la praxis además lo integra en ésta en forma de public moral, les ofrece modelos para la 
imitación» ${ }^{11}$. Puesto que la deshumanización hiriente pone en peligro al sistema, éste se sirve de la civilización como instrumento de dominación y somete a los miembros de la sociedad recreándolos a su imagen y semejanza. La deshumanización se vuelve inmanente al sistema, que ya no necesita excluir a nadie de la «cultura» porque ésta se ha convertido en el instrumento con el que todos quedan incluidos. La ideología, en el sentido de una mediación entre autonomía y dominación, ya no es necesaria, porque ya no hay nada que temer de la autonomía:

«La sociedad de intercambio instiga a sus hijos a perseguir metas sin cesar, a vivir orientados testarudamente hacia ellas, los ojos absorbidos por el beneficio que quieren atrapar, sin mirar ni a derecha ni a izquierda. Quien se sale de la senda está amenazado de ruina. La inmediatez coactiva impide a los seres humanos reconocer justo el mecanismo que los mutila: éste se reproduce en su conciencia sumisa» ${ }^{12}$.

A pesar de todo, no debemos olvidar que el sistema sigue siendo antagonista y la apariencia de que el conflicto de clases ha sido pacificado es eso, pura apariencia. No han sido suprimidas las dependencias fundamentales, aunque la dominación sobre los seres humanos que los convierte en una función de su propio aparato productivo se vuelva cada vez más anónima. A escala internacional se manifiestan las contradicciones de clase como contradicción entre países extremadamente ricos y países extremadamente pobres. La producción sigue realizándose bajo el imperativo de la maximización del beneficio y se mantiene el predominio del interés por la revalorización del capital en detrimento de las necesidades objetivas de los consumidores. Contra toda apariencia y a pesar de la abundancia cuantitativa de bienes, los individuos son estafados en relación a su calidad de vida. «Incluso allí donde impera la abun- dancia de bienes, ésta se encuentra como bajo una maldición. La necesidad, que tiende a convertirse en apariencia ilusoria, contagia a los bienes con su carácter ficticio» ${ }^{13}$. Basta considerar el hecho de que siga existiendo pobreza en la sociedad de la abundancia para constatar la irracionalidad de la situación. Así pues, el antagonismo no ha sido superado y «sólo a través del interés por el beneficio y de la fractura inmanente a toda la sociedad se mantiene hasta hoy chirriando, quejumbrosamente, con sacrificios indecibles, el engranaje» ${ }^{14}$.

Ahora bien, en esta situación toda afirmación de la inmediatez y sustancialidad del individuo es engaño, una mediación que se ignora y desconoce a sí misma. Es más, cuando el individuo atomizado, en cuanto sujeto volcado de modo prioritario hacia la pura autoconservación y constituido por el dominio de la naturaleza y las relaciones de intercambio - que no se puede encontrar a sí mismo en la realidad social antagonista - busca en la afirmación de la inmediatez de sus intereses individuales la certeza de sí que le niega la sociedad, entonces es cuando de modo más rotundo se realiza y consuma el dominio de la universalidad antagonista a través suyo. En el mismo principium individuationis se esconde la ley que rige el curso del mundo ${ }^{15}$. La afirmación de la sustancialidad absoluta del yo en medio de una sociedad antagonista es, por tanto, no sólo apariencia ilusoria, sino también transfiguración engañosa del orden existente, justificación de la mala positividad ${ }^{16}$. Por eso lo concreto y singular sólo puede pensarse como todavía no existente ${ }^{17}$. Esto le da la razón a Hegel, que reconoció de modo insobornable la prepotencia de lo universal, aunque lo transfigurara ilusoriamente en Idea. En ella hay de verdad que «lo singular, en la figura invertida del aislamiento impotente y entregado a lo universal, está dictado por el principio de universalidad invertida» ${ }^{18}$. 


\section{La debilidad del yo y el empobrecimiento de la experiencia}

Con la progresiva eliminación de la base económica de la responsabilidad individual y de la capacidad moral de decisión fruto de la creciente monopolización desaparece también la posibilidad de ganar en la socialización la distancia necesaria respecto al aparato social. La indiferencia frente al individuo, que se manifiesta en la industria de la cultura y en la persecución de los judíos, y que en su eliminación sistemática en los campos de exterminio llega al extremo más horroroso, es inherente a la tendencia social global. La economía se puede permitir cada vez menos el costoso factor «individuo». La instancia psíquica, de la que todavía necesitaba el capitalismo liberal y que concedía al individuo una cierta libertad, por mucho que ésta estuviera atada a la ley del interés y el beneficio, se ha convertido en un factor perturbador de la planificación social y económica en el capitalismo tardío. Todas las dimensiones de la individuación tienen que ser controladas, es decir, neutralizadas.

Esa supresión de la distancia se hace patente sobre todo en el proceso de burocratización diagnosticado por M. Weber, que extiende la planificación y el gobierno más allá del sistema político al mundo cotidiano de los individuos.

Según Adorno, asistimos a un creciente entrelazamiento de las burocracias políticas, económicas y culturales que limita considerablemente los espacios de acción individuales o los somete más decididamente a los imperativos administrativos. En el capitalismo tardío disminuyen los restos de realidad social todavía «no organizados» y aumenta la rapidez con que los nuevos espacios no planificados se convierten en objeto de planificación política o económica. Esta ampliación de la planificación administrativa es la que percibe Adorno como una amenaza para la vida individual y la configuración no instrumental de las relaciones sociales.

La omnipotencia del aparato suprime la distancia y la tensión entre individuo y colectividad, así como entre sujeto y realidad, distancia que sería necesaria para defenderse de la aniquilación. La creciente autonomización y autorregulación de la racionalidad técnica junto a su despliegue en el complejo tecnológico, bajo cuyo imperio se encuentran la burocracia y la administración en cuanto poderes institucionalizados, producen ese miedo del individuo anónimo y deformado, para el que la complejidad de la técnica y la desproporcionalidad del aparato administrativo adquieren el carácter irracional del destino o del hado mítico. La coacción de la sociedad, de sus estructuras y formas de organización, es aceptada como si poseyese una fatalidad irrevocable, lo que en el fondo no hace sino poner de manifiesto el grado de integración de la conciencia de los individuos.

En todas las instancias sociales dominan estructuras que predisponen, endurecen y someten a los individuos al dominio, tanto social y psicológicamente como en sus formas de conciencia, hieren permanentemente su narcisismo y los cosifican convirtiéndolos en objetos dependientes del poder social. El endurecimiento estructural del sujeto, que en esencia ya encontramos en el orden burgués, se convierte en sus formas extremas en una debilidad del yo sometido a la autoridad. Las condiciones sociales avanzadas de aislamiento, sometimiento, coacción a la adaptación y renuncia llevan a un debilitamiento progresivo de la conciencia independiente. Una vez debilitado de esta manera el yo capaz de decidir, en su lugar aparecen disposiciones autoritarias y agresivas del carácter o mentalidades patológicamente estereotipadas.

La debilidad del yo hoy, que no es simplemente psicológica, sino en la que el mecanismo psíquico registra la impotencia real del indivi- 
duo frente al aparato socializador, estaría expuesta a una dosis insoportable de agravio narcisista, si no se buscara una compensación a través de la identificación con el poder y la grandeza del colectivo ${ }^{19}$.

La «debilidad del yo» expresa según Adorno la configuración psíquica que se corresponde con la liquidación del individuo en la sociedad tardocapitalista. Adorno posee una concepción realmente dialéctica del yo, y esto tanto si nos referimos a los aspectos tratados por la teoría de la libido, como a los aspectos abordados por la teoría de la sociedad. El yo no sólo se constituye a través de los conflictos entre los impulsos libidinosos y los procesos de represión de los mismos, sino que también confluyen en él las tensiones de la realidad social antagonista. Esto hace que los intentos de ajuste entre las tendencias internas y las exigencias sociales se produzcan siempre en constelaciones conflictivas y estén enredados en contradicciones.

El interés por la autonomía y la posibilidad de afirmación de sí mismo no se encuentran en una armonía preestablecida con las exigencias sociales de adaptación, que es el precio para asegurar la autoconservación. Si no quiere ser expulsado del engranaje social, el individuo tiene que acatar las reglas de juego que dicta la situación dominante, pero las exigencias que se derivan de este acatamiento van asociadas a renuncias que no son razonables a primera vista. Ante esto caben dos posibilidades: enfrentarse de modo consciente a la represión social poniendo en peligro la autoconservación o poner en marcha maniobras de suavización y pacificación que impidan tener que soportar grandes mermas de la autoestima. Adorno considera que esta segunda forma es la predominante.

Las exigencias provenientes del exterior se han vuelto tan masivas y el individuo tan débil frente a ellas, que las renun- cias que le imponen no pueden ser internalizadas y convertidas en elementos de la propia conciencia, pero tampoco puede el yo identificarse con ellas. Dominado por el temor más o menos consciente tanto a los reveses sociales como a las privaciones psíquicas, termina renunciando a toda protesta contra las exigencias sociales en muchos casos carentes de sentido.

La adaptación a las situaciones y los procesos sociales, en que consiste la historia y sin los que le hubiera sido muy difícil a los seres humanos seguir existiendo, se ha sedimentado en ellos de tal manera, que decrece la posibilidad de escapar, aunque sólo sea en la conciencia, sin conflictos pulsionales insoportables. Están identificados - triunfo de la integración - hasta en sus formas más internas de comportamiento con aquello que les sucede. [...] El proceso vive de que los seres humanos deben su vida también a aquello que les es infligido. [...] Si en otro tiempo las ideologías actuaban como cemento de unión, éste se ha deslizado hacia la prepotente situación existente en cuanto tal, por un lado, y hacia la constitución psicológica de los seres humanos, por otro $^{20}$.

Debido a esta polarización, la adaptación ya no está mediada por la constitución de una instancia propia, que si bien interioriza las pretensiones provenientes de la sociedad, también permite un distanciamiento reflexivo frente a las mismas. Por eso la adaptación que realiza el yo permanece externa a él y queda quebrada su resistencia frente a dichas exigencias. Con esta última consideración podría parecer que Adorno critica una falta de equilibrio entre las distintas instancias - ello, yo y super yo- y sus pretensiones y la incapacidad de mediación y sublimación, es decir, de desplazamiento o «ennoblecimiento» de los impulsos libidinales, tal como plantea Freud. Con ello estaría asumiendo como ideal un «yo integrado» que tiene su base en la solución exitosa del complejo de Edipo, es decir, en la internalización del super yo que da ori- 
gen a la conciencia y a los sentimientos de culpa, pero que promete una regulación autónoma ${ }^{21}$. Sin embargo, Adorno dista mucho de considerar un ideal el yo integrado en el sentido freudiano:

La meta de la «personalidad bien integrada» es rechazable, porque le exige al individuo aquel balance de fuerzas que no existe ni debería existir en la sociedad establecida, dado que dichas fuerzas no poseen el mismo derecho. [...] Su integración sería una falsa reconciliación con el mundo irreconciliado, y acabaría probablemente en la «identificación con el agresor», pura máscara del sometimiento. [...] La persona «auténtica» en el sentido del planteamiento de Freud, esto es, la no desfigurada por represiones, sería casi idéntica en la sociedad adquisitiva existente a la fiera con saludable apetito, y con ello habríamos dado en el clavo de la utopía abstracta de un sujeto realizado independientemente de la sociedad ${ }^{22}$.

El modelo freudiano de explicación de la constitución del yo adquiere bajo la perspectiva de la Teoría Crítica un carácter histórico social. El ideal de Freud no es sólo la persona consciente que a través de un proceso doloroso no exento de represiones se convierte en dueño del ello. También es el varón creador de cultura, negador de los impulsos libidinales, desligado de los vínculos (con la madre) y sublimador. El super yo, que es interiorizado y entroncado a través de ese proceso y gracias a esa relación con la autoridad, en el sentido de una interiorización masoquista de la agresión, juega un papel fundamental en el desarrollo del yo. Éste resulta tan contradictorio y ambivalente como la subjetividad burguesa en cuanto tal, pues es portador de una dimensión represiva y otra emancipadora. El proceso de la interiorización del super yo y de la identificación con el padre es para cada sujeto un proceso de sufrimiento, que genera por así decirlo el yo, pero que también lo endurece y conforma sado masoquistamente: el sujeto se convierte en su propia instancia disciplinadora.
Este sujeto masculino, en cuanto sujeto patriarcal y volcado en la consecución de objetivos y, no en última instancia, en cuanto promotor de la barbarie, se encuentra en el centro de la crítica de Adorno: la autonomía en su forma burguesa sólo es pensable al precio del distanciamiento frente a la naturaleza propia y exterior, así como frente a otros sujetos, y del dominio de todo ellos. Incluso los objetivos eróticos, la necesidades pulsionales del Eros, están fundidos con la violencia, el sometimiento y las fantasías de apoderamiento referidas al propio yo y a los otros. Los elementos sado masoquistas son parte de la interiorización psicosocial de la autoridad y la violencia represivas, de la conformación histórica del yo y la conciencia, y pertenecen al proceso de constitución de la autonomía y el sujeto burgueses.

Pero, en la posibilidad de fracaso de la integración de las instancias que intervienen en la constitución del individuo, Freud conserva la conciencia de la ambigüedad del proceso de dicha constitución. Basta que se produzca una carencia amorosa importante para que desaparezca la tensión entre el yo y el super yo, con lo que este último no puede ser entroncado en el sujeto como instancia moral propia, permanece extraño al yo y provoca que las agresiones que nacen en él o que experimenta posteriormente sean proyectadas directamente hacia fuera. Además, cuando la renuncia libidinal extrema no es compensada por el amor, las necesidades (objetual) libidinosas son proyectadas de nuevo sobre el yo y reconvertidas en una desmesurada libido narcisista. Por otro lado, si fracasa la identificación con la autoridad, ésta permanece exterior al sujeto y la conciencia y las decisiones morales tienen que seguir siendo dependientes de autoridades externas. Se produce un antagonismo insostenible entre el apetito narcisista orientado hacia la omnipotencia deseada en los orígenes y la experiencia continua de pequeñez y limitación que desmienten dicha orientación. Este antagonismo está a la base de los 
intentos de engrandecer narcisistamente al yo por medio de la identificación con el colectivo o por las fantasías de omnipotencia.

Lo importante desde el punto de vista de Adorno es no convertir estas tensiones que forman parte constitutiva de la génesis del sujeto en invariantes psíquicas o en «determinaciones antropológicas» ${ }^{23}$. Hay que tener en cuenta que las condiciones sociales e históricas alteran el acceso del yo a la satisfacción de los impulsos, a una sublimación no represiva, a una fortaleza del yo sin acorazamiento bajo el principio de la autoconservación y a una socialización solidaria sin represión adicional. En este sentido es en el que la situación de los individuos en el capitalismo tardío, situación responsable de un especial debilitamiento de los seres humanos y de su subjetividad, produce nuevas formas agudizadas de empobrecimiento y regresión psicosociales. Aquellas condiciones que confieren fuerza al individuo frente a la sociedad han sido prácticamente eliminadas. Las formas mediadas de subjetividad, de capacidad de experiencia y disfrute, el alcance de la sublimación y la necesidad de ella, etc., son sustituidas cada vez más por la intervención directa de la sociedad en la economía pulsional de los seres humanos. El sujeto del siglo xx pierde su autonomía, su fuerza moral y espiritual, la experiencia marcadamente placentera y su capacidad de resistencia frente a la presión social a la adaptación.

Cuando el yo es demasiado débil para desarrollar la capacidad de integrar los deseos pulsionales, que a menudo actúan de forma avasalladora, las rígidas pretensiones del super yo y las exigencias de la realidad, los conflictos internos no pueden ser resueltos y llevan a reacciones angustiosas y opresoras. Los individuos se convierten en el curso de la fracasada ontogénesis de su proceso de socialización en «cautivos de su propio yo debilitado» ${ }^{24}$. La adaptación al poder o las convenciones y la identificación con la dureza, el dinero, el rendimiento o el poder, que en realidad son imposiciones de la sociedad, se convierten en determinantes de yo debilitado, que proyecta su odio hacia todos los que real o supuestamente se sustraen a esas imposiciones. Incapacitado para establecer un sistema consistente y duradero de valores morales autónomo, se ve obligado a acogerse a poderes sociales más poderosos, de los que hace depender sus decisiones morales.

Puesto que la rabia que produce el tener que someterse a los poderes sociales opresores no puede dirigirse contra ellos, el yo debilitado acaba desviándolos contra sí mismo o proyectándolos hacia algo exterior más débil. Bajo estas condiciones es como si la economía libidinal exigiese un chivo expiatorio ${ }^{25}$. Estamos ante un carácter dependiente y no integrado que reacciona «hacia los más fuertes con sumisión y hacia los más débiles con desprecio» ${ }^{26}$. Aquí se encuentra el origen del pensamiento estereotipado característico:

Se puede suponer que las personas en las sociedades modernas -incluso por lo demás «inteligentes» o «informadas»- recurren a explicaciones primitivas y simplificadoras de los acontecimientos humanos porque muchos de los pensamientos y observaciones necesarios para una adecuada interpretación no son aceptados, puesto que están cargados afectivamente y producen ansiedad; el yo débil no está en condiciones de asumirlos en sus esquemas de pensamiento ${ }^{27}$.

Esta limitación esquemática de la percepción y la conciencia va frecuentemente unida al mecanismo de la proyección que está a la base de los prejuicios. Sobre otras personas o sobre grupos identificados son proyectados los propios deseos reprimidos, las debilidades inaceptadas y los aspectos desagradables de sí mismo. Esto puede dar paso a la agresión si ésta cuenta con cierta sanción social o es respaldada por el poder, lo que dado el caso permite una revaloración del yo débil a través de 
una gratificación narcisista por identificación con el propio colectivo y devaluación del grupo ajeno $\mathrm{y}$, además, una descarga desbocada de las agresiones destructivas. El yo débil no es capaz de percibir el mundo en una forma que haga justicia a su complejidad y al carácter anónimo de sus estructuras, porque esa forma hiere el narcisismo individual y colectivo. Esto lleva a una personalización de las transformaciones que sufre el mundo económico, en realidad determinadas de modo abstracto: «los inmigrantes tienen la culpa de que yo pierda el trabajo».

Las formas en que se presenta el yo debilitado: el convencionalismo en la percepción de los fenómenos, la estereotipia en la formación del juicio y en las valoraciones, la clasificación de las personas en fuertes y débiles - y la correspondiente dependencia y sometimiento a los fuertes y triunfadores, así como la pretensión de someter a los débiles-, la incapacidad para diferenciar, la coactividad, etc., quedan focalizadas de modo singular en el empobrecimiento de experiencia. Adorno ha analizado con incomparable finura las diferentes manifestaciones del empobrecimiento de la experiencia que supone la descomposición de la individualidad en el capitalismo tardío. Aquí nos limitaremos a presentar una de ellas: la destruida relación con los muertos, tema del que se ocupa repetidamente. Adorno percibe aquí un síntoma de «que hoy la experiencia esta enferma» ${ }^{28}$, porque empobrecimiento $\mathrm{o}$, incluso, destrucción de la experiencia se producen allí donde se quiebra la continuidad del recuerdo consciente y de la memoria inconsciente.

El sometimiento de los individuos bajo el aparato social, económico y cultural estrecha y empobrece el mundo experiencial. La mediación de la sociedad totalizadora establece el primado de la producción y el intercambio y exige una adaptación de la capacidad de percepción, reacción y pensamiento de los sometidos a ella. Así, del mismo modo que el propio pasado que no se doblega aquí y ahora a las exigencias de la producción mediada socialmente ha de ser neutralizado por tratarse de un factor perturbador, esta sociedad también reprime todo duelo que se opone al funcionamiento sin contratiempos del mecanismo de producción: «Lo que sucede a todos los sentimientos, el desprecio de aquello que no tiene ningún valor en el mercado, le sucede de manera más destemplada a aquello de lo que ni siquiera es posible sacar un restablecimiento psicológico de la fuerza de trabajo, al duelo. Éste se convierte en estigma de la civilización, en sentimentalidad asocial, que delata que todavía no se ha conseguido del todo juramentar a los seres humanos en torno al reino de los fines» ${ }^{29}$.

La indiferencia creciente frente a los muertos tiene su correspondencia en la carencia de significación del individuo más allá de la función que cumple en el todo social. La reducción progresiva del ser humano a función dentro del universo funcional en que se convierte la sociedad está al servicio de la reemplazabilidad de los individuos.

Al no ser percibida la muerte más que como una separación de un ser vivo de la unión de la sociedad, finalmente dicha sociedad la ha domesticado: morir sólo confirma ya la absoluta irrelevancia del ser vivo natural frente al absoluto social. [...] Lo que han perpetrado los nacionalsocialistas con millones de seres humanos, el registro estandarizado de vivos como si fueran muertos, luego la producción en masa y el abaratamiento de la muerte, proyecta su sobra sobre aquellos que para reír se inspiran en los cadáveres. Lo decisivo es la asunción de la destrucción biológica en la voluntad social consciente. Sólo una humanidad para la que la muerte se ha vuelto tan indiferente como sus miembros, una humanidad que ha muerto para sí misma, puede imponerla de modo administrativo a incontables seres ${ }^{30}$.

La impermeabilización del sistema frente a lo cualitativamente otro sólo puede conseguirse neutralizando o impidiendo una 
experiencia no reglamentada. Esta incapacidad para la experiencia es generada socialmente y tiene en el intercambio su modelo: el «igual por igual» del intercambio elimina de sí aquello que no queda recogido en el importe final: la sustancia vital de los sujetos, el tiempo cualitativo, el recuerdo, la tradición, etc., todo lo que en la sociedad burguesa racionalizada es degradado a irracionalidad ${ }^{31}$. "Cuanto aquí y ahora no muestra su utilidad social en el mercado carece de valor y es olvidado» ${ }^{32}$. Qué otra cosa es la cosificación si no ese olvido que acompaña la reificación del sujeto ${ }^{33}$. Por eso la emancipación respecto al dominio de la tradición prolonga la tradición del dominio, porque esa emancipación se apoya en una impermeabilización del sujeto frente a su génesis, aunque el sufrimiento bajo la coacción que dicho proceso representa haga que la impermeabilización sea siempre frágil. Y precisamente porque la fuente del sufrimiento no se agota, la sociedad se ve obligada a desarrollar una industria cultural del olvido, que sostiene la falsa reconciliación entre lo universal y lo singular ${ }^{34}$.

A pesar de la potencia de esa falsa reconciliación, Adorno no dejó de constatar que los individuos no se dejan engañar del todo por el ilusionismo de la industria de la cultura y sus mensajes. Aparentemente se trata de una constatación contradictoria. Por un lado, perciben la apariencia ilusoria y la perciben como motor del conformismo, pero, por otro lado, su comportamiento como consumidores del mercado mediático no se ve afectado por esa percepción. Para explicar ese modelo de reacción contradic- torio, Adorno desarrolla el teorema de la «conciencia desdoblada». Se disfruta poco más o menos de manera coercitiva del valor de sensación de la oferta de la industria cultural («hostilidad contra el disfrute en el disfrute»), pero, por otro lado, la ubicación social de los individuos en sus contextos de vida reales los preserva de tomar por verdaderos los modelos de interpretación de la industria de la cultura.

Ya en un texto inédito de Adorno de 1942, con el título «Esquema de la industria cultural», se habla de un «límite de la cosificación», que viene dado por el hecho de que los sujetos no puedan dejar de serlo del todo. El claro índice de que las intervenciones monopolizadoras de la expansiva industria cultural se quiebren a causa de la subjetividad de los individuos, es que necesita de una estrategia circular de construcciones de realidad y producciones de sentido permanentemente renovadas, en una palabra, de la reproducción permanente de lo siempre igual. Ese «esfuerzo desesperado», esa coacción a la repetición permanente «es el único indicio de esperanza, de que la repetición sea inútil, de que los seres humanos no sean atrapables» ${ }^{35}$. Más tarde escribiría Adorno con más sobriedad, desde el punto de vista de un análisis del presente con acento sociológico, que «los intereses reales de los individuos son todavía lo suficientemente fuertes como para resistir dentro de un límite a la captación total. Esto cuadraría con el pronóstico social de que una sociedad cuyas contradicciones esenciales siguen existiendo sin disminuir, tampoco puede ser completamente integrada en la conciencia» ${ }^{36}$.

\section{NOTAS}

1 «La situación en la que desaparece el individuo» - escribe Adorno - «es al mismo tiempo la situación desbocadamente individualista, en la que "todo es posible"» $(M M$, p. 168). La siglas $D A, M M, \ddot{A} T h$ y $N D$ se refieren respectivamente a las obras: Dialektik der Aufklärung (t. 3), Minima Moralia (t. 4), Äthetis- che Theorie (t. 7) y Negative Dialektik (t. 6) en la edición Th. W. Adorno, Gesammelte Schriften, 20 tomos, Fráncfort d. M., Suhrkamp, 1970-1986, que se cita en otros casos como $G S$ y número de tomo.

${ }^{2} D A$, p. 145 . Sobre esta cuestión se pueden consultar entre otros trabajos: H. Schweppenhäuser, «Das 
Individuum im Zeitalter seiner Liquidation. Über Adornos soziale Individuationstheorie», en Archiv für Rechts- und Sozialphilosophie, vol. 57, núm. 1, 1971, pp. 91-115; H. H. Kappner, «Adornos Reflexionen über den Zerfall des bürgerlichen Individuums», en $\mathrm{H}$. L. Arnold (ed.), Theodor W. Adorno, Múnich, 1983, pp. 44-63; St. Müller-Doohm, «Denken im Niemandland. Adornos bürgerliche Antibürgerlichkeit», en Leviathan, núm 3, 1997, pp. 381-395; Th. Bonacker, «Ohne Angst verschieden sein können. Individualität in der integralen Gesellschaft», en D. Auer et al. (eds.), Die Gesellschaftstheorie Adornos. Themen und Grundbegriffe, Dramstadt, 1998, pp.117-143; D. Kipfer, Individualität nach Adorno, Tubinga, 1998.

${ }^{3} \mathrm{El}$ proceso por el que los miembros de la sociedad se convierten en individuos libres y autónomos, en sujetos del acontecer económico y cultural lo resume Adorno del siguiente modo: «Cuando la economía libre de mercado desplazó al sistema feudal y necesitó tanto del empresario como del asalariado libre, se formaron esos tipos no sólo en un sentido profesional, sino también antropológico; aparecieron conceptos como los de la responsabilidad propia, la previsión, el individuo que se basta a sí mismo, el cumplimiento del deber, pero también el del rígido imperativo de la conciencia, la vinculación interiorizada a autoridades. El individuo mismo, cuyo nombre seguimos utilizando hoy, no se remonta si atendemos a su sustancia específica más allá de Montaigne o el Hamlet, en todo caso hasta el renacimiento temprano italiano» (Th. W. Adorno, «Individuum und Organisation», en $G S$, t. 8, p. 450$)$.

${ }^{4} M M$, p. 169.

${ }^{5}$ Cfr. ND, p. 259.

${ }^{6} \mathrm{Cfr}$. Institut für Sozialforschung (ed.), Soziologische Exkurse. Nach Vorträgen und Diskussionen, Fráncfort d. M., 1983, p. 49.

${ }^{7}$ Op. cit., p. 49.

${ }^{8}$ El valor de la tendencia a la monopolización en la economía o de la tendencia a la organización de la economía, la política, la cultura, etc., según más o menos el modelo de las mafias y el significado que había que atribuir a ambas como claves explicativas del capitalismo y su relación con el nacionalsocialismo constituía uno de los temas clave de las discusiones del Instituto en el exilio. Las dos posiciones encontradas, la de F. Pollock y la F. L. Neumann, coincidían en la constatación de una evolución del capitalismo hacia la monopolización, pero disentían sobre la cuestión de si esta tendencia había producido un vuelco hacia un capitalismo de Estado en el que la función reguladora del mercado estaba siendo sustituida por la intervención y regulación directas de la economía por parte del poder político, lo que podía suponer una estabilización del sistema económico, pese a sus contradicciones, de consecuencias terribles, como el nacionalsocialismo ponía ante los ojos. Neumann afirmaba frente Pollock que el incremento de la función de la política que se manifestaba en el fascismo y que se prolongó en las democracias postfascistas era un producto del desarrollo del mismo capitalismo monopolista, es decir, de su tendencia a servirse de la burocracia estatal para realizar una planificación de la economía (cfr. los textos más importantes de esta discusión en M. Horkheimer et al., Wirtschaft, Recht und Staat im Nationalsozialismus. Analysen des Instituts für Sozialforschung, 1939-1942, H. Dubiel y A. Söllner (eds.), Fráncfort d. M., 1981). Es probable que Horkheimer y Adorno al decantarse por la teoría de F. Pollock sobre el capitalismo de Estado no fueran capaces de captar hasta qué punto la formación de monopolios sigue estando sujeta a la ley de la acumulación, y lejos de eliminar la competitividad y el mercado, resultan ser su reverso dialéctico. Sin embargo, su impresión, a la vista del Estado nacionalsocialista o estalinista y el New Deal norteamericano, de asistir a un proceso de consolidación de un capitalismo autoritario postliberal les ayudó a agudizar la mirada para los cambios cualitativos de la dominación moderna. Para otros autores, sin embargo, este decantamiento fue el principal responsable del giro de la Teoría Crítica hacia una filosofía negativa de la historia y hacia lo que consideran el pesimismo cultural de la Dialéctica de la Ilustración (cfr., entre otros, M. Gangl, «Staatskapitalismus und Dialektik der Aufklärung», en íd. y G. Raulet, Jenseits instrumenteller Vernunft. Kritische Studien zur «Dialektik del Aufklärung», Fráncfort d. M., 1998, pp. 158-186). Para un análisis de la problemática relación de Adorno con la economía cfr. R. Johannes, «Das ausgesparte Zentrum. Adornos Verhältnis zur Ökonomie», en G. Schweppenhäuser (ed.), Soziologie im Spätkapitalismus. Zur Gesellschaftstheorie Theodor W. Adornos, Darmstadt, 1995, pp. 41-67, donde se aborda también su posición respecto a la tesis de Pollock (pp. 51 ss.).

9 Th. W. Adorno, «Reflexionen zur Klassentheorie», en GS 8, p. 384.

${ }^{10}$ Op. cit., p. 389.

${ }^{11}$ Op. cit., pp. 390 ss.

12 Íd., «George und Hofmannsthal. Zum Briefwechsel, 1891-1906», en GS, t. 10, p. 227.

${ }^{13}$ Íd., «Spätkapitalismus oder Industriegesellschaft?», en $G S$, t. 8, p. 365 .

${ }^{14}$ Íd., «Gesellschaft», en, GS, 8, p. 15.

${ }^{15}$ Cfr. $M M$, p. 172.

${ }^{16}$ Cfr. $M M$, pp. $171-175$.

${ }^{17}$ Cfr. $\ddot{A T h}$, p. 203.

${ }^{18} \mathrm{ND}$, p. 338.

19 Íd., «Meinung Wahn Gesellschaft», en GS, t. 10, p. 580

${ }^{20}$ Íd., «Gesellschaft», en $G S$, t. 8, p. 18.

${ }^{21}$ Jessica Benjamin ha criticado desde la perspectiva feminista que Adorno y Horkheimer se mantengan fieles al modelo edípico, según el cual la interiorización de la autoridad paterna es al mismo tiempo la condición de posibilidad de la autonomía (cfr. J. Ben- 
jamin, «Die Antinomien des patriarchalischen Denkens. Kritische Theorie und Psychoanalyse», en W. Bonß y A. Honneth (eds.), Sozialforschung als Kritik. Zum sozialwissenschaftlichen Potential der Kritischen Theorie, Fráncfort d.M., 1982, pp. 426-455; también íd., Die Fesseln der Liebe. Psychoanalyse, Feminismus und das Problem der Macht, Fráncfort d. M., 1993, pp. 53-56 y 155-171). Desde su punto de vista la incoherencia se produce entre el modelo psicosocial de explicación de la debilidad del yo y la crítica de la dialéctica de la civilización como internalización del dominio. En el primero se haría responsable de la debilitación del yo a la debilitación de la figura paterna en la nueva situación económica del capitalismo tardío, debilitación que estaría impidiendo una solución adecuada del problema edípico. El individuo integrado, es decir, aquel que ha conseguido una interiorización de la autoridad paterna y por medio de ello ha logrado constituir su conciencia como instancia autónoma, es el que está en condiciones de ofrecer resistencia a las exigencias de autoridades externas. Con ello se convierte a la internalización de la autoridad en base de la autonomía y la autoconciencia del yo. Pero es precisamente esa internalización de la dominación lo que se convierte en objeto de la crítica de la civilización como introversión del sacrificio que encontramos, por ejemplo, en la Dialéctica de la Ilustración. Según J. Benjamin, esta paradoja pone de manifiesto que en el teorema de la debilitación del yo Adorno y Horkheimer quedan apresados en el modelo criticado por ellos mismos de la dolorosa interiorización del dominio y su tranformación en una conciencia basada en la exclusión de lo difuso, de lo pulsional, de lo «otro». J. Benjamin critica además el modelo edípico en sí mismo, ya que no es neutral desde el punto de vista del género. En el amor identificador edípico el padre es idealizado y la madre devaluada. El padre, como representante del mundo exterior, personifica la autonomía. Dado que la niña no es reconocida con el mismo valor que el niño, en la fase edipal se reproduce la forma más radical de desvalorización de la feminidad. A la niña se le niega la deseada autonomía a través de la identificación con el padre. Por el contrario, la teoría intersubjetiva de la personalidad que defiende J. Benjamin ve en el proceso de reconocimiento mutuo entre madre y niño/a en la fase más temprana de su evolución la condición de posibilidad para la consolidación de la subjetividad. El modelo interaccional sustentado en las relaciones tempranas entre la madre y el niño/a prevé un «equilibrio paradójico entre el reconocimiento y la autoconservación» (íd., Die Fesseln der Liebe..., p. 48).

La cuestión que conviene dilucidar es si Adorno, apoyado en el modelo edípico, pretende defender la sociedad burguesa temprana frente a la tardía o si más bien pretende explicar el vuelco dialéctico de la una en la otra. Resaltar las diferencias entre una autonomía relativa encadenada, sin embargo, a las instancias que llevan a cabo desde el inicio su disolución, por un lado, y una pérdida casi completa de la autonomía por medio de una poderosa integración de los individuos en el capitalismo tardío, por otro, no significa que se convierta en ideal el primer término de la comparación. En la estructura patriarcal de la sociedad burguesa se encuentra inscrita la dinámica que lleva a la disolución de la autonomía subjetiva bajo la presión directa al conformismo. La formación de la autonomía relativa en la fase temprana de sociedad burguesa gana su valor relativo sólo en relación con la destrucción de la autonomía, pero no se convierte por ello en único modelo posible $\mathrm{y}$, menos aún, deseable de formación de la autonomía. Si esto es así, Adorno no defiende un modelo patriarcal de sociedad, sino que diagnostica su descomposición, sin que la alternativa de una subjetividad emancipada aparezca a la vista.

${ }^{22}$ Th. W. Adorno, «Zum Verhältnis von Sociologie und Psychologie», en GS, 8, pp. 65 ss.

${ }^{23}$ Op. cit., p. 61.

${ }^{24}$ Th. W. Adorno y M. Horkheimer, «Vorurteil und Charakter», en GS, t. 9, p. 369.

${ }^{25} \mathrm{Cfr}$. Th. W. Adorno, Studies in the Authoritarian Personality, en GS 9, p. 200.

${ }^{26}$ R. Wiggershaus, Die Frakfurter Schule. Geschichte, Theoretische Entwicklung, Politische Bedeutung, Múnich, 1989, p. 175.

${ }^{27}$ Th. W. Adorno, Studies in the Authoritarian Personality, en GS, t. 9, p. 204.

${ }^{28}$ DA, p. 243.

${ }^{29} D A$, p. 244

${ }^{30} M M$, pp. 263 ss.

${ }^{31}$ Cfr. Íd., «Über Statik und Dynamik als soziolgische Kategorien», en $G S$, t. 8, p. 230.

32 Íd., «Über Tradition», en $G S$, t. 10, p. 311.

${ }^{33}$ Cfr. $N D$, p. 64; DA, 263.

${ }^{34}$ Cfr. DA, p. 151.

35 Íd., «Das Schema der Massenkultur», en GS, t. 3, p. 333.

${ }^{36}$ Íd., «Freizeit», en $G S$, t. 10.2, p. 655. 